\title{
An Evaluation of Learner's Perception and Engagement Towards Campus Preparation
}

\author{
Dipali D. Awasekar ${ }^{1}$ \\ ${ }^{1}$ Department of Information Technology, Walchand Institute of Technology, Solapur \\ 1dipali.awsekar@gmail.com
}

\begin{abstract}
:
Campus placement drives in a nutshell combines all the processes when a Company visits a college premise with a goal of hiring the students who are well-suited for a job in the company. The procedure of hiring a candidate varies from company to company but one thing remains common throughout all the companies i.e. Aptitude qualifying test. Aptitude test is an examination that attempts to determine and measure a person's ability to acquire, through future training, some specific set of skills (intellectual, motor, and so on). This study examines the student's preparation inclination who opted for the campus placement drive held in the Institute. It included research questions like in how many companies the student was placed in, name and package of the companies. A total of 21 students responded.
\end{abstract}

Keywords: E -Learning, Campus Preparation, Students Engagement

\section{Introduction}

Campus placement drives in a nutshell combines all the processes when a Company visits a college premise with a goal of hiring the students who are well-suited for a job in the company. The procedure of hiring a candidate varies from company to company but one thing remains common throughout all the companies i.e. Aptitude qualifying test. Aptitude test is an examination that attempts to determine and measure a person's ability to acquire, through future training, some specific set of skills (intellectual, motor, and so on). The tests assume that people differ in their special abilities and that these differences can be useful in predicting future achievements. General, or multiple, aptitude tests are similar to intelligence tests in that they measure a broad spectrum of abilities (e.g., verbal comprehension, general reasoning, numerical operations, perceptual speed, or mechanical knowledge).

The campus placement process includes activities like aptitude test, group discussion, technical interview, personal/HR interview. The need for preparing for Campus placement; it is seen as a general trend that most of the students in their engineering life have acquired specific technical skills through their academics. But while studying for their course they tend to neglect the aptitude part of placement. Most of them realize this during their final year of engineering, just as the companies are about to visit the campus. Majority of the students start preparing for the aptitude test just couple of days before the eventual test. Even while preparing the students do not have crystal clear idea about which topics to be focused on and usually run into chaos which later hampers their chances of cracking the exam.

The conventional approach of students while preparing for placement exams is by contacting the senior students who have taken the exams in the past, or simply by visiting the company website and referring to their syllabus but due to various reasons some students do not know the proper strategy for preparation and end up in confused state of mind. The analysis of this research will aid the students by providing them a tentative guideline also to know about various companies and target a specific company and prepare for it well in advance.

\section{Research questions}

This study aims to examine students who opted for the Campus placement drive at WIT College. We asked these research questions:

1. Number of campus placement exams given by the students

2. Whether the student was placed or not in a company, if yes then was he placed in more than one company

3. Name and package of the company.

4. Important topics which needed to be studied in order to crack the aptitude test of the company.

\section{Research Method}

A) Participants

The participants were 21 Final year students from I.T. department of WIT College Solapur. The students had registered for the Campus placement drive held in WIT College The placement drive is conducted every year for the Final year students who want to acquire a job. Different companies visit the college throughout the year and hire students based on their eligibility and criteria and through various tests conducted by the company.

B) Data sources, Procedure and Analysis

Survey: A fifteen-question online survey was created using Google Forms. The survey included questions on demographic information and the experience of students while they were participating in the Placement Drive. 
Both Multiple choice and open-ended questions were used. Sample questions included:

Department name

Number of companies you have appeared for

Number of companies you are placed in

Name of the company

Important topics to be prepared for the company

Interviews: All student participants were asked if they were willing to be interviewed, knowing the importance of the campus preparations of getting a placement/job for the successive batches (Third year); students showed their willingness for the interview.

A structured face to face interview was conducted by the team, out of 21, 15 students were called for the interview.

Sample interview questions include:

Please describe your preparations for the campus placement.

Specify any obstacles which you faced during the preparation

Specify the mistakes which you felt that could be avoided during the preparations

Procedure: The google form survey was distributed during the first week of February 2019, using google classroom. The participants were informed that their participation was non-anonymous and were give two days for their responses. Twenty-one responses were collected.

Analysis: Figure 1 indicates that $90.5 \%$ of students were placed in one company, i.e. is out of twenty-one students, nineteen students secured a job. Remaining two students had yet to find placement.

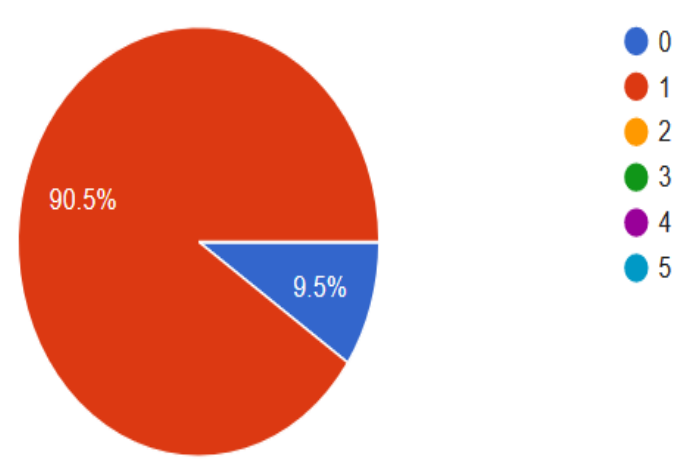

Figure 1. Numbers of companies students are placed in.

Subsequently figure 2 gives us information regarding the number of companies, different students have appeared for. $9.5 \%(n=2)$ got placed in the very first company they appeared for. $14.3 \%(n=3)$ landed the job in their $2 n d$ campus placement exam while $14.3 \% \quad(n=3)$ students appeared for three companies before getting placed. $28 \%$ $(n=6)$ of the students had to appear for five or more companies to be placed. $\mathrm{N}=3$ students, which contributed to $14.3 \%$, had to appear for Ten different companies. The highest number of companies appeared by the student without a placement was Twenty which occurred in the case of only one student. i.e. $4.8 \%$.

\section{Methodology}

This study was also aimed to know the feasibility of learning video media developed. The development model was divided into 3 stages namely Planning, Design, and Development. Data collection techniques used interview method, literature method and instrument method. In the next stage, learning video was validated by the subject matter experts. The result of the research showed that video learning has been successfully made on basic $\mathrm{C}$ programming subjects that consist of 24 video lectures by 6 faculties. These LeD were rolled out by all the $\mathrm{C}$ programming faculty to more than $600+$ students. Based on the learning video validation result, the percentage of learning video's eligibility is $92.5 \%$ from subject matter experts, $95.9 \%$ of learners.

This methodology is useful for an individual teacher or an institute to create good quality video resources those could be placed on YouTube for open access. And unlike live/college classes, you can fast-forward, repeat \& rewind any part of your lecture or training - as many times as required! This allows our students to achieve truly exceptional results - regardless of their age or background.

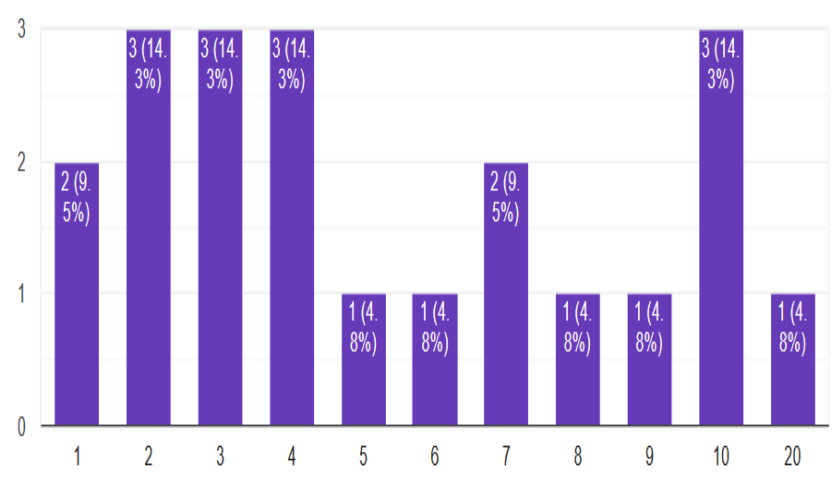

Figure 2. Numbers of companies' students have appeared for.

The following figures give us details about the topics which are mainly focused in the aptitude examination conduct in the placement process by the companies.

Figure 3 indicates that topics like Percentages, Probability, Time and Work are of utmost importance while preparing for the exam as $85.7 \%(n=18)$ students have checked it, while Quadratic equation was focused the least-9.5\% $(n=2)$. Time Speed Distance and permutation combination were subsequently important with $81 \%(n=17)$ and $66.7 \%(n=14)$ respectively reporting them. Boats and Stream and Number System were checked by $52.4 \%(n=11)$ students. H.C.F. and L.C.M. was marked by $47.6 \%(n=10)$. 


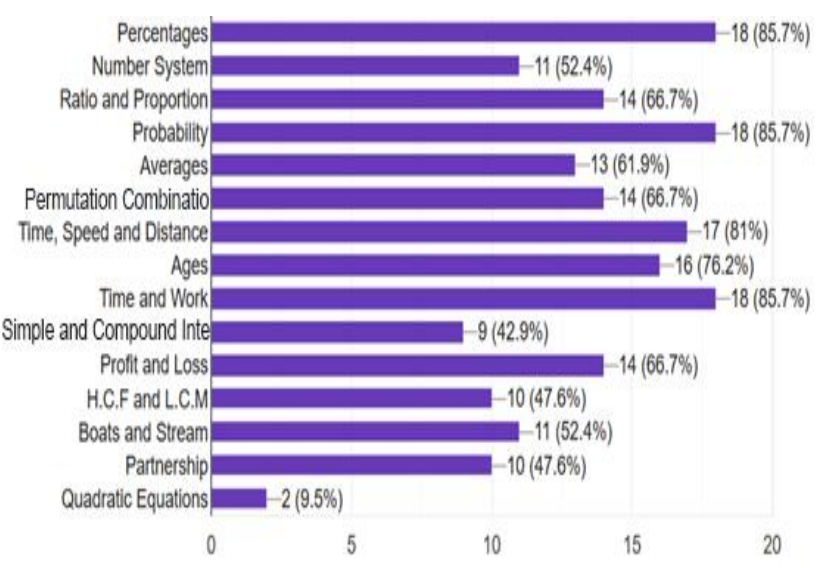

Figure 3. Topics from Quantitative Section.

Figure 4 gives us information about the Verbal section in which $95.5 \%(n=20)$ students have checked the Reading Comprehension as the most asked topic in the exam, Error Correction was $2^{\text {nd }}$ with $85.7 \%(n=18)$ students marking them, while Jumbled Paragraphs, Synonyms, One Word Substitution had the $3^{\text {rd }}$ most priority with $76.2 \%(n=16)$ students selecting these topics.. Vocabulary and Sentence Formation were the topics prepared by $42.9 \% \quad(n=9)$ students. Spellings topic had the least weightage according to the students with only $4.8 \%(n=1)$ students preparing it.

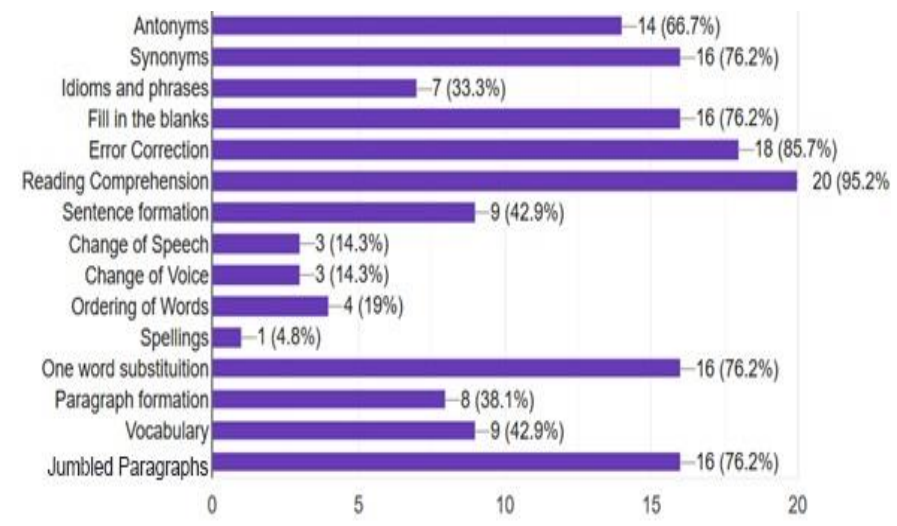

Figure 4. Topics from Verbal Section

Figure 5 sheds light on the topics from Logic and Reasoning Section. In which $90.5 \%(n=19)$ prepared for Direction sense while Data sufficiency, Seating Arrangement questions were reported by $85.7 \%(n=18)$ of the students. $81 \%(n=17)$ students checked Coding and Decoding, Blood Relations while Number series and Venn Diagrams were selected by $71.4 \%(\mathrm{n}=15)$ and students $6.7 \% \quad(\mathrm{n}=14)$ respectively. Only $14.3 \% \quad(\mathrm{n}=3)$ students marked Logical games, Deduction, Letter and Symbol series which was the least among other topics.

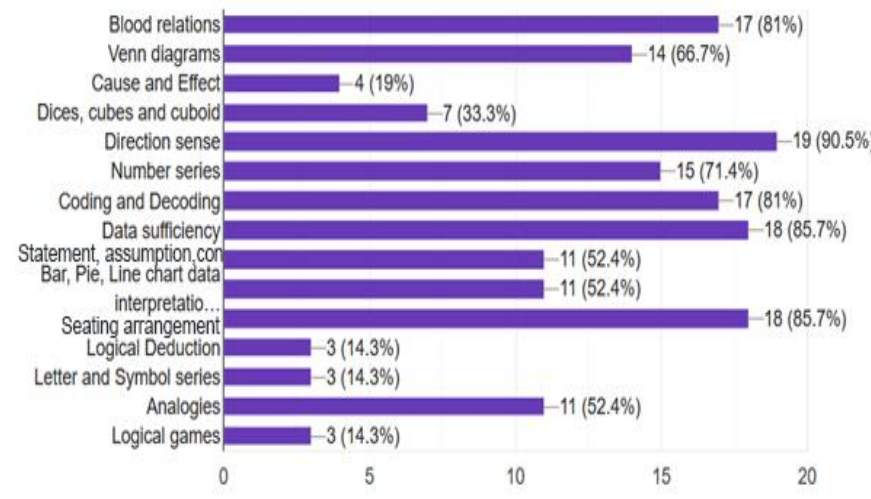

Figure 5. Topics from Logic and Reasoning Section.

\section{Dipali D. Awasekar}

Department of Information Technology,

Walchand Institute of Technology,

dipali.awasekar@gmail.com

5. Discussion and Findings

In order to evaluate the students' perception towards campus a survey questionnaire of 15 questions regarding students participation in campus placement was created.

The following are the some findings from the same: For Quantitative Section; $85.7 \%$ i.e. Eighteen out of Twenty-one students practised and solved questions related to Probability, Time and Work, Percentage. Since these were relatively common and most asked topics in the exams, students felt a need to practise them more. Time, speed, distance- was reported by $81 \%$ of the students which means 17 students had recommended it. $76.2 \% \quad(n=16)$ did their practise sessions on question related to Ages. $66.7 \%$ students recommended topics like Ratio and Proportion, Permutation-Combination and Profit and Loss. Number system, Boats and Stream were reported by $52.4 \%$ making it Eleven students out of Twenty-one. H.C.F. and L.C.M., Partnership was marked by $47.6 \%$ of the students which suggests that Ten students checked them. Nine students i.e. $42.9 \%$ out of total checked Simple and Compound Interest. Quadratic Equations was voted least by only Two students out of Twenty-one; $9.5 \%$ of the total. For Verbal Section; Reading comprehension was the most important topic as $95.2 \%$ i.e. Twenty students out of Twenty-One reported it. Error correction had the 2nd priority with $85.7 \%$ making Eighteen students out of the total reporting it. Synonyms, Jumbled paragraphs, Fill in the blanks, One-word substitution equally had the share of $76.2 \%$ with Sixteen students. Followed by Antonyms having $66.7 \% \quad(n=14)$. Sentence formation and Vocabulary both bagged $42.9 \%$ with Nine students each. Similarly Paragraph formation had $38.1 \%$ of the share with Eight students. $33.33 \% \quad(n=7)$ students reported Idioms and phrases while Ordering of words 
was done by $19 \%$ with Four students. Change of speech and Change of voice both had the same students' percentage of $14.3 \%(n=3)$.

\section{References}

[1] Dipali D Awasekar , " Effect of Program Visualization to Teach Computer Programming in a Resource Constrained Classroom" 2013/12/18 Conference, 2013 IEEE Fifth International Conference on Technology for Education (t4e 2013)

[2] Anderson, R. E. (1992). Social impacts of computing: Codes of professional ethics. Social Science Computing Review, 10(2), $453-$ 469.

[3] Chan, T. W., Roschelle, J., Hsi, S., Kinshuk, Sharples, M., Brown, T. et al. (2006). One-to-one technology-enhanced learning: An opportunity for global research collaboration. Research and Practice in Technology-Enhanced Learning, 1(1), 3-29.

[4] Conger, S., \& Loch, K. D. (1995). Ethics and computer use. Communications of the ACM, 38(12), 30-32.

[5] Jonassen, D. H., Peck, K. L., \& Wilson, B. G. (1999). Learning to Solve Problems with Technology: A Constructivist Perspective (2nd Edition). Columbus, $\mathrm{OH}$ : Prentice Hall.

[6] Mackay, W. E. (1995). Ethics, lies and videotape. In I. R. Katz, R. Mark, L. Marks, M. B. Rosson, \& J. Nielsen (Eds), Proceedings of CHI'95 (pp. 138-145). Denver, Colorado: ACM Press.

[7] Schwartz, M., \& Task Force on Bias-Free Language of the Association of American University Press (1995). Guidelines of Bias-Free Writing. Bloomington, IN: Indiana University Press. 